\title{
Health Service Needs From a Household Perspective: an Empirical Study in Rural Empty Nest Households in China
}

\section{Xueyan Cheng}

Shanghai Health Research and Development Center

Liang Zhang ( $\nabla$ zhanglianghust@126.com )

Huazhong University of Science and Technology

\section{Research Article}

Keywords: health services need, household unit, empty nest household, family collective model, empirical research

Posted Date: August 3rd, 2021

DOI: https://doi.org/10.21203/rs.3.rs-757920/v1

License: (c) (i) This work is licensed under a Creative Commons Attribution 4.0 International License.

Read Full License 
Health service needs from a household perspective: An empirical study in rural empty nest households in China

Xueyan Cheng ${ }^{1,2}$, Liang Zhang ${ }^{2 *}$

1 Shanghai Health Research and Development Center, Shanghai, 200032, China

2 School of Medicine and Health Management, Tongji Medical College, Huazhong University of Science and Technology, Wuhan, Hubei, 430030, China

Email Address:

Xueyan Cheng xycheng6972@hust.edu.cn

Liang Zhang $\quad$ zhanglianghust@126.com

* Corresponding author: Liang Zhang. E-mail: zhanglianghust@126.com.

Address for correspondence: No.13 Hangkong Road, Qiaokou District, School of Medicine and Health Management, Tongji Medical College, Huazhong University of Science and Technology, Wuhan, Hubei, 430030, China 


\section{Abstract}

Objective: Household is a fundamental unit in many fields. This study was to analyse consistency degree and people's health service needs from the perspective of household.

Methods: A multi-stage random sampling was conducted. A total of 7293 individuals in 2715 households were interviewed, and 1606 individuals in 803 empty-nest households were enrolled in this study. A questionnaire was used to ask each individual about their health service needs in empty nest households. The consistency degree was calculated based on their consistent answers to the questionnaire, and a correlation analyse was used to study the relationship of individuals' health service needs in the same empty nest households. A family collective model was used to analyse household-based health service needs.

Results: Individual's needs consistency rates in empty nest households, such as diagnosis and treatment service(H1), follow-up service for chronic disease $(\mathrm{H} 2)$, telemedicine care(H3), physical examination service(H4), health education service(H5), mental healthcare(H6), and Chinese traditional medicine service(H7) were $40.30 \%, 89.13 \%, 98.85 \%, 58.93 \%, 57.95 \%, 72.84 \%$, and $63.40 \%$, respectively. Service needs of H1, H3, H4, H5, H7 for individuals in the same empty nest households had significant correlations with each other $(\mathrm{r}=0.404,0.177,0.286,0.265$, $0.220, \mathrm{P}<0.001)$. Health service needs from a perspective of household in rural China mainly included H1 (12.4\%), H4 (44.2\%), H5 (26.9\%) and H7(18.9\%). 
Conclusions: Individuals in the same household are highly consistent with each other in health service needs. Individuals could affect other members' health service needs in their households, when one of them get illness, their spouse would likely to have same health service needs to avoid getting disease or to keep health. In this study, health service needs in empty nest households are mainly concerned with health promotion and maintenance services, which could be an indicator for primary care to improve the effectiveness of service delivery, such as family doctor and family-based health insurance system. Also, more focus should be paid on households that need great help on different health services.

Keywords: health services need; household unit; empty nest household; family collective model; empirical research 


\section{Introduction}

Local context associated with individual health and well-being has become an important research topic [1]. The contextual environment, such as the school [2-4], community [5,6], county, and state levels [7], has a considerable effect on people's health. In general, family context is directly related to the formation of its members' values, consumption habits and daily routines.

Individuals' health could affect other member's health service needs in the same households. For example, for patients with chronic disease, their family caregivers may also experience a host of problems, like anger, fear, and depression [8]. Thus, they may suffer diverse needs and health concerns. People's health is also associated with who they are living with. Support from patients' family, especially the support from their spouse, could affect their health-seeking behavior [9]. And because of the important role of family members, some countries like Canada tried to expand their effort to actively involve patients, family members in health service improvement and system redesign initiatives [10]. Hughes found that married couples (age 51-61) living alone or with children only are the most advantaged in health, but single women living with children disadvantaged on all health outcomes [11]. In China, the elderly live alone and live with their children showed both advantages and disadvantages in health [12]. Imbalanced distribution of health capitals could explain the differences, and these differences can be affected by individual's role, health status, or even educational level in a household. 
In China, there are many health services were delivered based on a household unit. In 2016, Chinese government proposed a family doctor system, in which general practitioners would establish a long-term service relationship with families that signed contract with them. The family doctors would offer $95 \%$ of primary care and play a key role as the primary health gatekeeper [13]. But due to a lack of several essential uniform features such as health insurance support, appropriate incentive mechanisms, objective evaluation methods, as well as effective way of delivering service, so there was some difficulty to implement the family doctor contracting services in China [14]. Besides, some health promotion programming tried to consider families, but for lacking of funding and policy, it is difficult to maintain family-centered interests in associating interventions [15]. Therefore, it is important to clarify health service needs from a household perspective, which would be references for services like family doctor and health promotion policies to be more feasible in China.

An empty-nest household in China usually refers to households without kids or whose children have left their parents' home [16,17]. Often associated with low income, poor living conditions, and a lack of social and emotional support, residents in empty-nest households are more likely to be vulnerable to different health problems and irreversible decrease in function capacity [17-19]. Moreover, empty nest population usually consists of elderly people, that are likely to suffer from a high prevalence of chronic conditions and disability [20]. When their children move out of their homes, residents in empty nest households will feel the empty nest syndrome with symptoms such as loneliness, anxiety and frustration [21-23]. An investigation 
conducted in Sichuan, a western province in China, found that $30.11 \%$ of the empty nest elderly had anxiety-related symptoms [24]. These negative emotions are consistently tied to a subjective feeling of increased pain, disease and tiredness [25, 26].

The accelerated urbanisation and inequity of economic development in urban and country areas have resulted in the empty nest becoming a main family pattern in rural China. In 2014, the empty nests accounted for $51.1 \%$ of the elderly in China, and this proportion will reach to $90 \%$ by 2030 according to the China's National Committee on Aging [27]. The increase in empty nest households has brought a series of problems and thus has gained considerable attention from individuals, families, society, and the entire state [28]. In general, members in empty nest families are often concerned with poor health statuses because of lacking care from children, bad in mobility, and of high risk in chronic diseases.

Therefore, it is urgent to improve individual's health in empty nest households. This study was to find out if there exist consistency between individuals' health service needs, to figure out the relationship between individual's needs, and to explore the health service needs from a household perspective.

\section{Methods}

\section{Study design and data collection}

With a $95 \%$ confidence level, the calculation is based on the requirement that the absolute sampling error does not exceed 3\%. Due to the use of multi-stage complex 
sampling, the design effect will generally be between 2 and 2.5[29-33]. This study considers the design effect at 2.5.

$$
\begin{aligned}
& n_{i}=u_{a}^{2} \cdot p \cdot(1-p) / \delta^{2} \\
& N_{i}=n_{i} \cdot D E F F
\end{aligned}
$$

Formula (1) calculates the sample size of simple random sampling. $n_{i}$ represents the number of samples required for the $i$ stage. The $u_{a}$ corresponds to the inspection level of $u$ value, and $\delta$ is the allowable error. Formula (2) calculates the sample size of multi-stage stratified random cluster sampling. $N_{i}$ is the sample size of multi-stage stratified random cluster sampling. DEFF is sampling efficiency, referring to how many samples in this sampling process can provide the information that one sample could in a simple random sampling. The absolute sampling error is taken to be $21.338 \%$ of the chronic disease prevalence of the whole population based on the number of patients in China according to the 2013 National Health Service Survey, while the $u_{a}$ is 1.96 with a $95 \%$ confidence level [34]. Sampling efficiency could be affected by the intra-group correlation coefficient (ICC), sample stratification, the average number of respondents in each set, internal heterogeneity. Among them, the design efficiency of the National Census in China is 1.4, which serves as a reference value in this study.

$$
\begin{gathered}
n_{i}=\frac{u_{a}^{2} \cdot p \cdot(1-p)}{\delta^{2}}=\frac{(1.96)^{2} \times 0.21138 \times 0.78862}{(0.0211138)^{2}} \approx 1433 \\
N_{i} \approx 1433 \times 2.5=3583
\end{gathered}
$$

Therefore, the sample size in each county was 3583 individuals. According to the 
Fifth National Health Service Survey, the average amount of individuals per household was 2.9[34]. At last, a total of 1200 households in each county should be investigated.

This study was conducted in Sinan County in Guizhou Province and Dangyang County in Hubei Province. A multistage stratified random sampling strategy was used to select the households. Five townships in each county were selected randomly, and six villages were considered according to their distances away from each township. We conducted face-to-face interviews with almost 40 households in each of the 30 villages, and each individual in the household was questioned. Finally, we investigated 3983 residents in 1353 households.

The following criteria were used to select the empty nest households: 1) households with only two members in the house firstly entered the study; 2) households with two members must be spouses; 3) respondents must be living at the survey site for at least 6 months; 4) at least one member in empty-nest households could participate in the study via face-to-face interview. Finally, a total of 1606 empty nest people in 803 empty nest households were included $(803 \times 2=1606)$.

\section{Health service needs consistency rates}

According to individual's answer to the questionnaire, consistency rates of individual's health service needs could be calculated as:

$$
\begin{aligned}
& \text { Consistency rate }=\text { COUNT } n\left(x_{l i j}=x_{2 i j}, i=1,2, \ldots \ldots, \mathrm{N} ; j=1,2, \ldots \ldots, 8\right) / N \\
& x_{l i j} \text { refers to the health service needs of one individual in an empty nest }
\end{aligned}
$$


household, $x_{2 i j}$ and refers to the other individual's health service needs in the same empty nest household. When both selections of two individuals were the same, then this empty nest household would be counted into this formula. $i$ is the code of empty nest households, and $j$ refers to the code of different health service needs. $n$ is the number when $x_{1 i j}=x_{2 i j}$, and $N$ is the total count of empty nest households in this study.

\section{Healthcare need from a household perspective}

\section{Family collective model}

Becker first put up with the collective household model, in which the household is characterized as a collection of individuals. This model assumes that family consumption decision is the outcome of multi-person decision making. An intrinsic feature of the collective model is sharing rule, which governs the within-household distribution of household capitals. This sharing rule is always an indicator of bargaining power of individual household members. The ultimate consumption decision on each good or service is always along with general household characteristics, income levels, et al. But these factors only affect different weights on individuals' bargaining power in a household's model, but not the preferences of individual household members $[35,36]$.

When there are two individuals (1 and 2) in the same household consume a set of services, the health service needs in a household unit would be:

$$
\mathrm{H}(Q, q f, q m)=\max (Q, q f, q m) \quad\left\{b_{1} u f(\mathrm{Q}, \mathrm{qf}, \mathrm{qm})+b_{2} u m(Q, q f, q m)\right\}
$$

$Q$ refers to the public health service needs, $q f$ and $q m$ are the private health 
service needs. $u f$ and $u m$ are the expected health utility people would obtain from different health services. In this study, we investigated people's subjective health score, and the gap between their status to full-health status is the utility they would get from the health services. $b_{1}$ and $b_{2}$ refer to individuals' bargaining power in the same empty nest household, it could be affected by individual's education level, role in their family (whether or not the householder) and their objective health status valued by EQ-5D.

In this study, we take the mean score of different factors as individuals' bargaining power. The educational level was divided into three levels, the higher level of a individual, the stronger their bargaining power. If individual 1 is householder, then they have better bargaining power, then $b 1=1, \quad b 2=0$. The value estimated by EQ-5D refers to the objective health status.

\section{Results}

\section{Consistency rates of different health service needs in empty nest households}

In table 1, individuals in empty nest households have high consistency rates on follow-up service for chronic disease $(89.13 \%)$, telemedicine care $(98.85 \%)$, mental healthcare $(72.84 \%)$ and Chinese traditional medicine service $(63.40 \%)$ needs. But the consistency rates of diagnosis and treatment service, physical examination service, and health education service are relatively low. 
Table 1 consistency rates of different health service needs $(n=803)$

\begin{tabular}{lll}
\hline Health service needs & Frequency & Consistency rate $(\%)$ \\
\hline H1: diagnosis and treatment service & 323 & 40.30 \\
H2: follow-up service for chronic disease & 716 & 89.13 \\
H3: telemedicine care & 794 & 98.85 \\
H4: physical examination service & 441 & 54.99 \\
H5: health education service & 465 & 57.95 \\
H6: mental healthcare & 585 & 72.84 \\
H7: Chinese traditional medicine service & 509 & 63.40 \\
\hline
\end{tabular}

\section{Correlations between individual's health service need in empty nest households}

In table 2, health service needs include diagnosis and treatment service $(\mathrm{r}=0.404)$, telemedicine care $(\mathrm{r}=0.177)$, physical examination service $(\mathrm{r}=0.286)$, health education service $(\mathrm{r}=0.265)$, and Chinese traditional medicine service $(\mathrm{r}=0.220)$ of individuals in empty nest household have significant correlations with each other $(\mathrm{P}<0.001)$.

Table 2 correlations between individual's health service needs (r)

\section{Health service needs from a household perspective in empty nest households}

As shown in Table 3, individuals in empty nest households have similar subjective and objective health mean score. Individuals with educational level less than primary school accounted for over $50 \%$. Distribution of householders in both members were the same, and there were about $0.2 \%$ missing data. 
Table 3 Characteristics for each individual in empty nest households

\begin{tabular}{llll}
\hline Characteristics & Categories & Individual 1 & Individual 2 \\
\hline Subjective health score & Mean score & 69.95 & 67.69 \\
Objective health score & Mean score & 0.887 & 0.865 \\
Educational level & Less than primary school & $50.7 \%$ & $60.0 \%$ \\
& Junior and senior high school & $47.8 \%$ & $36.6 \%$ \\
& More than undergraduate & $0.3 \%$ & $0.8 \%$ \\
Householder & Yes & $74.5 \%$ & $25.5 \%$ \\
& No & $25.4 \%$ & $74.3 \%$ \\
\hline
\end{tabular}

From the results of family collective model, as shown in table4, households that with publicly health service needs as their household needs accounted for $93.4 \%$, and households that take one individual's health service needs as their household needs accounted for $5.7 \%$. The publicly needs at the household level mainly include physical examination service (43.3\%), and health education service $(24.9 \%)$. The needs at individual level mainly include diagnosis and treatment service (56.5\%), physical examination service $(65.2 \%)$, health education service $(63.0 \%)$ and Chinese traditional medical service $(45.7 \%)$. In general, the health service needs on empty nest households mainly include diagnosis and treatment service (12.4\%), physical examination service (44.2\%), health education service (26.9\%) and Chinese traditional medicine service $(18.9 \%)$. 
Table 4 health service needs from a household perspective (n,\%)

\begin{tabular}{llllll}
\hline \multirow{2}{*}{ Health service needs } & Publicly needs as & \multicolumn{3}{c}{ Individual needs as household needs } & \multirow{2}{*}{ Total } \\
\cline { 3 - 4 } & household needs & Individual 1 & Individual 2 & Total & \\
\hline H1 & $73(9.8)$ & $11(52.4)$ & $15(60.0)$ & $26(56.5)$ & $99(12.4)$ \\
H2 & $39(5.2)$ & $0(0.0)$ & $0(0.0)$ & $0(0.0)$ & $39(4.9)$ \\
H3 & $1(0.1)$ & $1(4.8)$ & $0(0.0)$ & $1(2.2)$ & $2(0.3)$ \\
H4 & $323(43.3)$ & $15(71.4)$ & $15(60.0)$ & $30(65.2)$ & $353(44.2)$ \\
H5 & $186(24.9)$ & $16(76.2)$ & $13(52.0)$ & $29(63.0)$ & $215(26.9)$ \\
H6 & $29(3.9)$ & $7(33.3)$ & $1(4.0)$ & $8(17.4)$ & $37(4.6)$ \\
H7 & $130(18.1)$ & $11(52.4)$ & $10(40.0)$ & $21(45.7)$ & $151(18.9)$ \\
Total & $746(93.4)$ & $21(2.6)$ & $25(3.1)$ & $46(5.7)$ & $799(100.0)$ \\
\hline
\end{tabular}

Notes: H1: diagnosis and treatment service; H2: follow-up service for chronic disease; H3: telemedicine care; H4: physical examination service; H5: health education service; H6: mental healthcare; H7: Chinese traditional medicine service

\section{Characteristics for health service needs from a household perspective}

According to Table 5, among the empty-nest households which take publicly health service needs as household needs are mainly male householders, accounting for 94.0\%. And $69.3 \%$ of these households have at least one individual who had illness within two weeks when we did the survey, $82.4 \%$ households had at least one individual with chronic disease. Households with one or two individuals had illness within two week or chronic diseases were more likely to take publicly health needs as household needs. 
Households that take one individual's health service needs as household needs are more concerned with the individual's health status. The individuals usually had a disease within two weeks $(100.0 \%)$ or had a chronic disease $(82.6 \%)$.

Table 5 Characteristics for health service needs from a household perspective (n, \%)

\section{Discussion}

In this study, individuals in empty nest households do have some health service needs in common with each other. It may credit to the same family context they have, where their family culture and living habits originate, resulting in individuals in the same household have similar health literacy and consumption value $[37,38]$. Thus, it is feasible to identify health service needs from a household perspective, and it could be of great help to make the limited health resources in a household more effective.

According to the results of this study, individuals in empty nest households had high consistency degree in health promotion and maintenance service needs. But for needs like diagnose and treatment service, which is mostly affected by people's subjective feeling about their health, as well as the disease severity, and people may have different health services needs even they get the same kind of disease [39]. Services focusing on health promotion and health maintenance are to coordinate the behaviors and strategies of society, household, and individuals to promote health, so people would like to have common service needs. And from the results of correlation analyse, individuals' health service needs in the same household have a significant relationship with each other. When one individual gets sick, it is usually for their 
spouse to worry about getting the same illness, and a publicly health service need is formed.

Health service needs from a household perspective are both dynamic and stable. For those get emergency illness or severe disease, it is more likely that the individual's health service needs should be satisfied firstly. The individual who get sick is dynamic in a household. But when both individuals in the same households have similar health status, or get some normal and chronic diseases, they may take publicly health service needs as their household needs [40]. Any individual's health problem can cause another individual's sense of crisis. For the individual who is not ill, it is more likely for them to improve their health awareness to maintain or promote health of all family members. Therefore, to identify the health care needs from a perspective of household is meaningful to improve people's health.

From this study, the health service needs from a household perspective are usually health maintenance and promotion services, such as physical examination services, health educational services, and Chinese traditional medicine services. Individuals in empty nest households are always suffering bad health status, weak economic support, and high risk of different diseases, so it is normal for them to only request a basic level of health, and to reduce the burden on their children in their later life [41]. Regular physical examination is an effective measure for empty nest individuals to discover health problems timely [42]. In China, it has implemented a policy of free physical examinations for people over 65 years, and was proved of effective [43]. Health education can popularize common disease prevention 
knowledge, chronic disease prevention, daily maintenance, and acute disease measures for residents in rural areas with low educational levels. This health education service provided by primary care institutions is the main source of health information for people in empty nest households [44], because most of them are unable to use smart phone and to understand complicated information from television.

In corresponding with the household needs, health services delivery should also pay more attention in a household-based way. Service providers not only need to focus on individual's health service needs, but also their family members. And from the characteristics for health service needs from a household perspective, it may be more efficient to provide services like health education to householders firstly, for householders had a good bargaining power in their family. And then, their spouse may have high degree of compliance for the services. Besides, empty-nest families usually face the dual suppression of health and economic crises, which are more likely to cause "poverty due to illness" and "return to poverty due to illness" when they have health problems [45]. Then, improving health status in rural area has become an important step to get rid of poverty. Therefore, a family-based health insurance system is encouraged in built in rural China. China has a long family culture, and it is feasible that Chinese health care system should have as its core family health saving accounts. It involves enrolment of spouse and children, and it can also include other members of the family. It could be an effective means to alleviate people's health pressure in empty nest households [46, 47].

There were some limitations in this study. First, only two-individual empty nest 
households were enrolled in this study. Empty nest households with only one individual and with grandchildren were excluded in this study. Second, due to the limitation of data collection, only the framework of family collective model was used in this study. Studies about household-based health service need further study.

\section{Ethics approval and consent to participate}

All procedures performed in studies involving human participants were in accordance with the ethical standards of the Ethics Committee of Tongji Medical College, Huazhong University of Science and Technology (IORG No: IORG0003571), and with the 1964 Helsinki declaration and its later amendments or comparable ethical standards. A verbal informed consent was obtained from all individual participants included in the study with the help of local government.

\section{Consent for publication}

Not applicable.

\section{Availability of data and materials}

The datasets used and/or analyzed during the current study are available from the corresponding author upon reasonable request. Contact information: zhanglianghust@,126.com.

\section{Competing interests}

The authors declare no conflict of interest.

\section{Funding}


The study was funded by National Natural Science Foundation of China (Grant No: 71734003)

\section{Author contribution}

ZL and CXY designed the study. CXY drafted and reviewed the manuscript. CXY analyzed the data and interpreted the results. ZL modified the manuscript. Both authors reviewed and approved the manuscript.

\section{Acknowledgement}

We would like to express our great appreciation to the participants in this study. We also thank all of the local government officers and medical staff on the assistance of organization. Moreover, we truly appreciate the help of research assistants on the data entry and management.

\section{References:}

[1] Liu J, Tian J, Yue P, Wang Y, Du X, Chen S. Living experience and care needs of Chinese empty-nest elderly people in urban communities in Beijing, China: A qualitative study. Int J Nurs Sci. 2015; 2: 15-22.

[2] Machry RV, Knorst JK, Tomazoni F, Ardenghi TM. School environment and individual factors influence oral health related quality of life in Brazilian children. Braz Oral Res. 2018; 32: e63.

[3]Maia C, Mendes FM, Normando D. The impact of oral health on quality of life of urban and riverine populations of the Amazon: A multilevel analysis. PLoS One. 2018; 
13: e0208096.

[4] Pereira S, Reyes A, Moura-Dos-Santos MA, Santos C, Gomes TN, et al. Why are children different in their moderate-to-vigorous physical activity levels? A multilevel analysis. J Pediatr (Rio J). 2020;96(2):225-232.

[5] Guedes RS, Piovesan C, Antunes JL, Mendes FM, Ardenghi TM. Assessing individual and neighborhood social factors in child oral health-related quality of life: a multilevel analysis. Qual Life Res. 2014; 23: 2521-30.

[6] Lothrop N, Hussaini K, Billheimer D, Beamer P. Community-level characteristics and environmental factors of child respiratory illnesses in Southern Arizona. BMC Public Health. 2017; 17: 516.

[7] Lin YH, McLain AC, Probst JC, Bennett KJ, Qureshi ZP, Eberth JM. Health-related quality of life among adults 65 years and older in the United States, 2011-2012: a multilevel small area estimation approach. Ann Epidemiol. 2017; 27: $52-58$

[8] Kilic ST, Oz F. Family Caregivers' Involvement in Caring with Cancer and their Quality of Life. Asian Pac J Cancer Prev. 2019;20(6):1735-1741.

[9] Ohashi A, Higuchi M, Labeeb SA, Mohamed AG, Chiang C, Aoyama A. Family support for women's health-seeking behavior: a qualitative study in rural southern Egypt (Upper Egypt). Nagoya J Med Sci. 2014;76(1-2):17-25.

[10] Abelson J, Humphrey A, Syrowatka A, Bidonde J, Judd M. Evaluating Patient, 
Family and Public Engagement in Health Services Improvement and System Redesign. Healthc Q. 2018;21(SP):61-67.

[11] Hughes ME, Waite LJ. Health in household context: living arrangements and health in late middle age. J Health Soc Behav. 2002 Mar;43(1):1-21.

[12] Li LW, Zhang J, Liang J. Health among the oldest-old in China: which living arrangements make a difference? Soc Sci Med. 2009 Jan;68(2):220-7.

[13] Fu P, Wang Y, Liu S, et al. Analysing the preferences for family doctor contract services in rural China: a study using a discrete choice experiment. BMC Fam Pract. 2020;21(1):148.

[14] Yuan S, Wang F, Li X, Jia M, Tian M. Facilitators and barriers to implement the family doctor contracting services in China: findings from a qualitative study. BMJ Open. 2019; 9(10):e032444.

[15] Barnes MD, Hanson CL, Novilla LB, Magnusson BM, Crandall AC, Bradford G. Family-Centered Health Promotion: Perspectives for Engaging Families and Achieving Better Health Outcomes. Inquiry. 2020; 57:46958020923537.

[16] Gao M, Li Y, Zhang S, Gu L, Zhang J, Li Z, et al. Does an Empty Nest Affect Elders' Health? Empirical Evidence from China. Int J Environ Res Public Health. $2017 ; 14$.

[17] Lv XL, Jiang YH, Sun YH, Ren CZ, Sun CY, Sun L, et al. Short form 36-Item Health Survey test result on the empty nest elderly in China: a meta-analysis. Arch 
Gerontol Geriatr. 2013; 56: 291-7.

[18]Liang Y, Wu W. Exploratory analysis of health-related quality of life among the empty-nest elderly in rural China: an empirical study in three economically developed cities in eastern China. Health Qual Life Outcomes. 2014; 12: 59.

[19]Zhang H. Who will care for our parents? Changing boundaries of family and public roles in providing care for the aged in urban China. Care Manag J. 2007; 8: $39-46$.

[20] Chatterji S, Byles J, Cutler D, Seeman T, Verdes E. Health, functioning, and disability in older adults--present status and future implications. Lancet. 2015; 385: $563-75$

[21] Chang Y, Guo X, Guo L, Li Z, Yang H, Yu S, et al. Comprehensive Comparison between Empty Nest and Non-Empty Nest Elderly: A Cross-Sectional Study among Rural Populations in Northeast China. Int J Environ Res Public Health. 2016; 13.

[22] Fahrenberg B. Coping with the empty nest situation as a developmental task for the aging female--an analysis of the literature. Z Gerontol. 1986; 19: 323-35.

[23] Pillay AL. Midlife depression and the "empty nest" syndrome in Indian women. Psychol Rep. 1988; 63: 591-4.

[24] Wang Z, Shu D, Dong B, Luo L, Hao Q. Anxiety disorders and its risk factors among the Sichuan empty-nest older adults: a cross-sectional study. Arch Gerontol Geriatr. 2013; 56: 298-302. 
[25] Pressman SD, Gallagher MW, Lopez SJ. Is the emotion-health connection a "first-world problem"? Psychol Sci. 2013; 24: 544-9.

[26] Geisser ME, Roth RS, Theisen ME, Robinson ME, Riley JR. Negative affect, self-report of depressive symptoms, and clinical depression: relation to the experience of chronic pain. Clin J Pain. 2000; 16: 110-20.

[27] Su D, Wu XN, Zhang YX, Li HP, Wang WL, Zhang JP, et al. Depression and social support between China' rural and urban empty-nest elderly. Arch Gerontol Geriatr. 2012; 55: 564-9.

[28] Liu J, Tian J, Yue P, Wang Y, Du X, Chen S. Living experience and care needs of Chinese empty-nest elderly people in urban communities in Beijing, China: A qualitative study. Int J Nurs Sci. 2015; 2: 15-22.

[29] Kaiser R, Woodruff BA, Bilukha O, et al. Using design effects from previous cluster surveys to guide sample size calculation in emergency settings. Disasters. 2006;30(2):199-211.

[30] Liu J, Zhang G. Research on the application of design effect in complex sampling-taking China’ s household survey as an example. J Appl Stat Manag. 2015; 34(4):628-635.

[31] UNICEF, Design and selecting the sample [R]. Available from: http://mics.unicef.org/files?job=W1 siZiIsIjIwMTUvMDQvMDIvMDgvMDAvMTkv ODEwL01JQ1MzX0NoYXB0ZXJfNF9fX0Rlc2lnbmluZ19hbmRfU2VsZWN0aW5n X3RoZV9TYW1wbGVfMDYwMjE5LnBkZiJdXQ\&sha=3d97a05358bb0e37. 
[32] Whitney Moore SP, Krishnamurty P, Wolter K. National longitudinal survey of youth 1997 Technical sampling report [R] 2000.

[33] $\mathrm{Hu}$ Y, Jia T. Exploration on the survey protocol of population structure changes. Popul Econ. 1992;1:40-43.

[34] Center for Health Statistics and Information, NHFPC. The Fifth National Health Service Survey and Analysis Report. Beijing: Chinese Union Medical University Press; 2015.

[35] Becker GS. Altruism in the Family and Selfi shness in the Market Place. Economica. 1981; 48:1-15.

[36] Cherchye L, De Rock B, Lewbel A, et al. Sharing Rule Identification for General Collective Consumption Models. Econometrica. 2015; 83(5): 2001-2041.

[37] Kim TY, Haider M, Hancock GR, Boudreaux MH. The Role of Health Literacy in Family Planning Use among Senegalese Women. J Health Commun. 2019; 24(3):244-261.

[38] Ishikawa H, Kiuchi T. Association of Health Literacy Levels Between Family Members. Front Public Health. 2019 Jun 19;7:169.

[39] Kaprio H, Suominen AL, Lahti S. Association between subjective oral health and regularity of service use. Eur J Oral Sci. 2012 Jun;120(3):212-7

[40] Samanta T, Chen F, Vanneman R. Living Arrangements and Health of Older Adults in India. The Journals of Gerontology Series B: Psychological Sciences and 
Social Sciences. 2014; 70(6):937-947.

[41] Zhai Y, Hu M. Association of empty nest with depressive symptom in a Chinese elderly population: A cross-sectional study[J]. J Affect Disord. 2015; 187:218-223.

[42] Ge D, Chu J, Zhou C, Qian Y, Zhang L, Sun L. Rural-urban difference in the use of annual physical examination among seniors in Shandong, China: a cross-sectional study. Int J Equity Health. 2017;16(1):86.

[43] Sun X, Chen Y, Tong X, Feng Z, Wei L, Zhou D, Tian M, Lv B, Feng D. The use of annual physical examinations among the elderly in rural China: a cross-sectional study. BMC Health Serv Res. 2014;14:16.

[44] Xu L, Meng Q, He S, et al. The effects of health education on patients with hypertension in China: A meta-analysis. Health Educ J. 2014; 73(2):137-149.

[45]Hu C, Yu W, Lv Y, et al. Study on the Health Status and Health Service Utilization of the Elderly of a Remote and Poor Village in a Mountainous Area in Jinzhai, Anhui[J]. Int J Environ Res Public Health. 2017; 14(4):408.

[46] Thi Thuy Nga N, FitzGerald G, Dunne MP. Family-Based Social Health Insurance for Informal Workers in Vietnam: Willingness to Pay and Its Determinants. Asia Pac J Public Health. 2018 Sep;30(6):512-520.

[47] Cao Y, Chen X, Fan R. Toward a Confucian family-oriented health care system for the future of China. J Med Philos. 2011 Oct;36(5):452-65. 

Table 2 correlations between individual's health service needs $(r)$

\begin{tabular}{|c|c|c|c|c|c|c|c|}
\hline Individuall & H1 & $\mathrm{H} 2$ & H3 & $\mathrm{H} 4$ & H5 & H6 & $\mathrm{H} 7$ \\
\hline $\mathrm{H} 1$ & $0.404 * *$ & 0.049 & 0.034 & 0.063 & -0.044 & -0.086 & -0.045 \\
\hline $\mathrm{H} 2$ & 0.059 & 0.003 & 0.004 & 0.026 & -0.036 & 0.006 & 0.025 \\
\hline H3 & 0.059 & 0.005 & $0.177 * *$ & 0.037 & 0.002 & 0.009 & 0.039 \\
\hline $\mathrm{H} 4$ & 0.003 & 0.033 & -0.004 & $0.286 * *$ & $0.115^{* *}$ & -0.013 & 0.015 \\
\hline H5 & -0.032 & -0.018 & 0.037 & $0.104 * *$ & $0.265 * *$ & -0.018 & 0.051 \\
\hline H6 & 0.005 & 0.022 & 0.026 & 0.015 & 0.024 & 0.053 & 0.036 \\
\hline $\mathrm{H} 7$ & 0.007 & 0.027 & 0.031 & -0.002 & $0.085^{*}$ & -0.035 & $0.220 * *$ \\
\hline
\end{tabular}

Notes: H1: diagnosis and treatment service; H2: follow-up service for chronic disease; H3: telemedicine care; H4: physical examination service; H5: health education service; H6: mental healthcare; H7: Chinese traditional medicine service. ${ }^{*} \mathrm{P}<0.05,{ }^{*} \mathrm{P}<0.001$. 
Table 5 Characteristics for health service needs from a household perspective (n, \%)

\begin{tabular}{|c|c|c|c|c|c|c|}
\hline & & \multicolumn{5}{|c|}{ Publicly needs as household needs } \\
\hline & & & \multicolumn{2}{|c|}{$\mathrm{n}$} & \multicolumn{2}{|r|}{$\%$} \\
\hline \multirow{11}{*}{$\begin{array}{c}\text { Family } \\
\text { characteristics }\end{array}$} & \multirow{2}{*}{$\begin{array}{l}\text { Householder's } \\
\text { gender }\end{array}$} & Male & \multicolumn{2}{|c|}{701} & \multicolumn{2}{|c|}{94.0} \\
\hline & & Female & \multicolumn{2}{|c|}{45} & \multicolumn{2}{|r|}{6.0} \\
\hline & \multirow{2}{*}{$\begin{array}{l}\text { Two-week } \\
\text { prevalence }\end{array}$} & both & \multicolumn{2}{|c|}{154} & \multicolumn{2}{|c|}{20.7} \\
\hline & & $\begin{array}{c}\text { One } \\
\text { individual }\end{array}$ & \multicolumn{2}{|c|}{335} & \multicolumn{2}{|c|}{47.7} \\
\hline & \multirow{4}{*}{$\begin{array}{l}\text { Chronic } \\
\text { disease }\end{array}$} & None & \multicolumn{2}{|c|}{236} & \multicolumn{2}{|r|}{31.7} \\
\hline & & Both & \multicolumn{2}{|c|}{228} & \multicolumn{2}{|c|}{30.7} \\
\hline & & $\begin{array}{c}\text { One } \\
\text { individual }\end{array}$ & \multicolumn{2}{|c|}{384} & \multicolumn{2}{|c|}{51.7} \\
\hline & & None & \multicolumn{2}{|c|}{131} & \multicolumn{2}{|c|}{17.6} \\
\hline & & \multicolumn{5}{|c|}{ Individual needs as household needs } \\
\hline & & & \multicolumn{2}{|c|}{ Individual 1} & \multicolumn{2}{|c|}{ Individual 2} \\
\hline & & & $\mathrm{n}$ & $\%$ & $\mathrm{n}$ & $\%$ \\
\hline \multirow{6}{*}{$\begin{array}{c}\text { Individual } \\
\text { characteristics }\end{array}$} & \multirow[t]{2}{*}{ householder } & Yes & 19 & 90.5 & 0 & 0.0 \\
\hline & & No & 2 & 9.5 & 25 & 100.0 \\
\hline & \multirow{2}{*}{$\begin{array}{l}\text { Two-week } \\
\text { prevalence }\end{array}$} & Yes & 21 & 100.0 & 25 & 100.0 \\
\hline & & No & 0 & 0.0 & 0 & 0.0 \\
\hline & \multirow{2}{*}{$\begin{array}{l}\text { Chronic } \\
\text { disease }\end{array}$} & Yes & 16 & 76.2 & 22 & 89.0 \\
\hline & & No & 5 & 23.8 & 3 & 12.0 \\
\hline
\end{tabular}

